OPEN ACCESS

Edited by:

Guanjie He,

University of Lincoln, United Kingdom

Reviewed by:

Pingwei Cai,

Fujian Institute of Research on the Structure of Matter (CAS), China

Zhishan Li,

Kunming University of Science and

Technology, China

*Correspondence:

Liangping Shen

20040480@hubu.edu.cn

Biao Zhang

zhbiao_1118@163.com

Specialty section:

This article was submitted to

Catalysis and Photocatalysis,

a section of the journal

Frontiers in Chemistry

Received: 09 September 2021

Accepted: 23 September 2021

Published: 14 October 2021

Citation:

Xiang $D$, Zhang $B$, Zhang $H$ and Shen $L$ (2021) One-Step Synthesis of Bifunctional Nickel Phosphide Nanowires as Electrocatalysts for

Hydrogen and Oxygen

Evolution Reactions.

Front. Chem. 9:773018.

doi: 10.3389/fchem.2021.773018

\section{One-Step Synthesis of Bifunctional Nickel Phosphide Nanowires as Electrocatalysts for Hydrogen and Oxygen Evolution Reactions}

\author{
Dong Xiang ${ }^{1}$, Biao Zhang ${ }^{1 *}$, Hongsheng Zhang ${ }^{1}$ and Liangping Shen ${ }^{2,3 *}$ \\ ${ }^{1}$ School of Mechatronics Engineering, Harbin Institute of Technology, Harbin, China, ${ }^{2}$ Hubei Yangtze Memory Labs, Hubei \\ University, Wuhan, China, ${ }^{3}$ Hubei Key Laboratory of Ferro and Piezoelectric Materials and Devices, School of Microelectronics, \\ Hubei University, Wuhan, China
}

The $\mathrm{Ni}_{2} \mathrm{P}$ nanowires were simply synthesized via a rapid one-step hydrothermal approach, in which deionized water, red phosphorus, nickel acetate, and hexadecyl trimethyl ammonium bromide were used as the solvent, phosphor and nickel sources, and active agent, respectively. The as-synthesized $\mathrm{Ni}_{2} \mathrm{P}$ nanowire clusters were composed of uniform nanowires with length of about $10 \mu \mathrm{m}$ and diameter of about $40 \mathrm{~nm}$. The $\mathrm{Ni}_{2} \mathrm{P}$ nanowires exhibited enhanced electrocatalytic activity for both hydrogen evolution reaction and oxygen evolution reaction This work provides good guidance for the rational design of nickel phosphides with unique nanostructures for highly efficient overall water splitting.

Keywords: nickel phosphide, nanowire, hydrogen evolution reaction, oxygen evolution reaction, hydrothermal

\section{INTRODUCTION}

Growing energy demands and worsening environmental issues have motivated a large amount of research into developing efficient energy conversion/storage systems for sustainable alternatives (Tan et al., 2020; Ji et al., 2021), e.g., Li-ion batteries (Chen et al., 2016; Zhang et al., 2017a; Li et al., 2017), supercapacitor (Wang et al., 2020; Zhao et al., 2021), water splitting (Wang et al., 2016a; Wang et al., 2016b; Swierk and Mallouk, 2017), and fuel cells (Debe, 2012). Hydrogen generated by water splitting is one of the key strategies for conquering these energy challenges (Kuang et al., 2017). However, the half-reactions of water-splitting, namely hydrogen evolution reaction (HER) and oxygen evolution reaction (OER), suffer from high overpotentials due to sluggish electrode kinetics (Huang et al., 2017). Efficient electrocatalysts, such as noble metal catalysts Pt, Ru, and Ir, are one of the core parts to improve the efficiency of the water decomposition process (Zhou et al., 2016; Zhang et al., 2017b). However, the high cost and scarcity of resources have severely restricted their largescale applications. Hence, it is fairly urgent to explore efficient, low-cost, and earth-abundant nonnoble bifunctional electrocatalysts for HER and OER.

In recent years, nickel-based compounds [oxide (Gong et al., 2014; Qiu et al., 2017; Zhang et al., 2018), hydroxide (Danilovic et al., 2012; Rao et al., 2016), sulfide (Feng et al., 2015; Zhu et al., 2016), and phosphide (Gan et al., 2020; Ji et al., 2021)] have displayed remarkable electrocatalytic activity and stability toward OER and HER, as bifunctional electrocatalysts (Vij et al., 2017). Among them, nickel phosphides could be considered as an efficient and promising candidate in numerous fields of electrochemistry including catalysis (Rao et al., 2016), lithium-ion batteries (Li et al., 2016a), and supercapacitors (Wan et al., 2017). Of note, nickel phosphides (especially metallic-phased phosphide, such as $\mathrm{Ni}_{2} \mathrm{P}$ ) are excellent catalysts for HER and OER due to their unique 
physicochemical properties imparting their high-efficiency and low overpotential (Feng et al., 2014; Liao and Huang, 2017). For example, Matthias Dries et al. (Menezes et al., 2016) reported two remarkably active nickel phosphides that delivered an overpotential of $295 \mathrm{mV}$ for $\mathrm{Ni}_{12} \mathrm{P}_{5}$ and $330 \mathrm{mV}$ for $\mathrm{Ni}_{2} \mathrm{P}$ at $10 \mathrm{~mA} \mathrm{~cm}^{-2}$ for $\mathrm{HER}$, and realized a low potential of 1.64 and $1.58 \mathrm{~V}$ at $10 \mathrm{~mA} \mathrm{~cm}^{-2}$ for OER in $1 \mathrm{M} \mathrm{KOH}$, respectively. $\mathrm{Ni}_{\mathrm{x}} \mathrm{P}_{\mathrm{y}}$ nanocatalysts are highly efficient at driving an overpotential of $1.57 \mathrm{~V}$ at $10 \mathrm{~mA} \mathrm{~cm}^{-2}$ in $1.0 \mathrm{M} \mathrm{KOH}$ for OER (Li et al., 2016b). $\mathrm{Ni}_{2} \mathrm{P}$ nanoparticles exhibit an overpotential of $0.2 \mathrm{~V}$ at $10 \mathrm{~mA} \mathrm{~cm}^{-2}$ in $0.1 \mathrm{M} \mathrm{KOH}$ for HER (Li et al., 2015). It is reported that another kind of $\mathrm{Ni}_{2} \mathrm{P}$ nanoparticle delivers an overpotential of $290 \mathrm{mV}$ at $10 \mathrm{~mA} \mathrm{~cm}^{-2}$ in $1 \mathrm{M} \mathrm{KOH}$ (Stern et al., 2015). However, the preparation approaches of metal phosphide special nanostructures mainly relies on the hightemperature (over $300^{\circ} \mathrm{C}$ ) oil phase method, e.g., $\mathrm{Ni}_{12} \mathrm{P}_{5}, \mathrm{Ni}_{2} \mathrm{P}$, and $\mathrm{Ni}_{5} \mathrm{P}_{4}$ nanocrystals $\left(320^{\circ} \mathrm{C}\right.$ ) (Pan et al., 2015), and two-step high-temperature (over $300^{\circ} \mathrm{C}$ ) gas-solid reaction, such as $\mathrm{CoP}$ nanoneedle (Wang et al., 2016c), CoP film $\left(450^{\circ} \mathrm{C}\right)$ (Hellstern et al., 2016), porous $\mathrm{Ni}_{2} \mathrm{P}\left(500^{\circ} \mathrm{C}\right)$ (Wang et al., 2016d), FeP nanorods $\left(500^{\circ} \mathrm{C}\right)$ (Xiong et al., 2016), and $\mathrm{Ni}-\mathrm{P}$ porous nanoplates $\left(300^{\circ} \mathrm{C}\right)$ (Yu et al., 2016). The low-energy consumption preparations of nickel phosphides with special nanostructures are rarely reported and hard to control, restraining the practical applications of nickel phosphides in electrocatalysis.

The special microstructures of nanowire clusters play a significant role in promoting catalytic activity because of their abundant edge active sites and facilitated charge (including electrons and ions) transfer path (Sivanantham et al., 2016; Tang et al., 2016). In this work, we report a facile one-pot synthesis of $\mathrm{Ni}_{2} \mathrm{P}$ nanowire clusters using the hydrothermal method and the as-prepared $\mathrm{Ni}_{2} \mathrm{P}$ nanowires exhibit enhanced electrocatalytic activity for both HER and OER.

\section{EXPERIMENTAL SECTION}

\section{Preparation of $\mathrm{Ni}_{2} \mathbf{P}$ nanowires}

In a typical experiment, $2 \mathrm{mmol} \mathrm{Ni}\left(\mathrm{CH}_{3} \mathrm{COO}\right)_{2} \cdot 4 \mathrm{H}_{2} \mathrm{O}, 9 \mathrm{mmol}$ red phosphorus, and $1 \mathrm{mmol}$ hexadecyl trimethyl ammonium Bromide (CTAB) were dissolved in $60 \mathrm{ml}$ pure water. Then, the above solution was transferred into a $100 \mathrm{ml}$ Teflon-lined stainless autoclave, and heated at $195^{\circ} \mathrm{C}$ for $30 \mathrm{~h}$. After cooling to room temperature, the collected precipitate was filtered and washed with water and ethanol, and then dried overnight.

\section{Materials Characterization}

$\mathrm{X}$-ray diffraction (XRD) patterns of the samples were analyzed

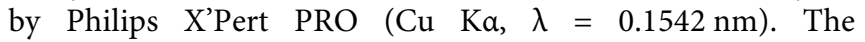
microstructures of the samples were examined by scanning electron microscope (SEM, FEI Quanta 200) and the refined microstructures were probed by transmission electron microscopy (TEM, Philips, Tecnai G20). X-ray photoelectron spectroscopy (XPS) spectra were collected on a Kratos AXIS Ultra DLD-600W XPS (a monochromatic $\mathrm{Al} \mathrm{Ka}(1,486.6 \mathrm{eV}$ ) as $\mathrm{X}$-ray source).

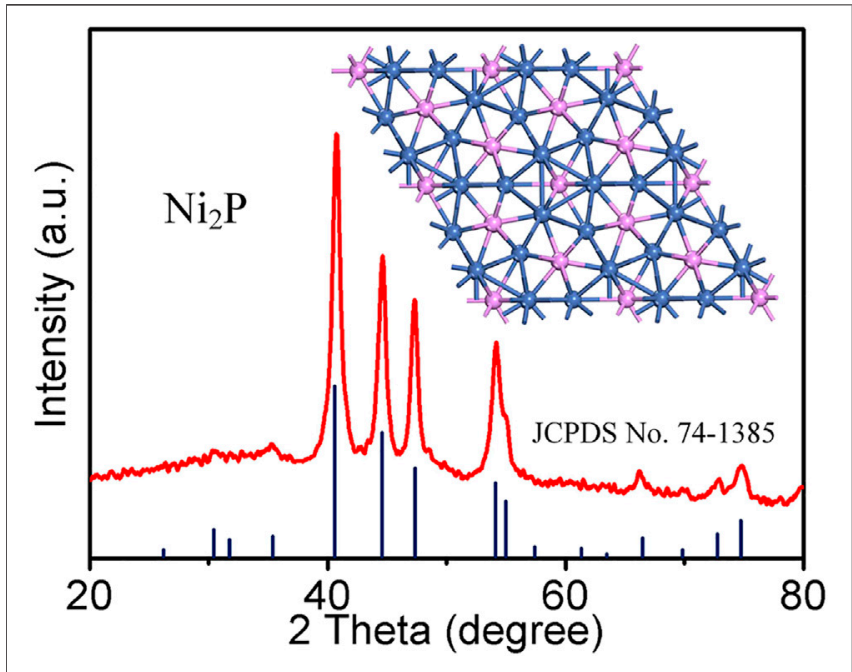

FIGURE 1 | XRD pattern of the as-synthesized $\mathrm{Ni}_{2} \mathrm{P}$ nanowires.

\section{Electrochemical Measurement}

For the preparation of the working electrode, $5 \mathrm{mg}$ electrocatalyst and $1 \mathrm{mg}$ Ketjen black were dispersed in $968 \mu \mathrm{L}$ of water/ethanol (volume ratio 4:1) mixture with addition of $32 \mu \mathrm{L}$ Nafion solution (5 wt\%). After ultrasonic dispersion for $30 \mathrm{~min}, 4 \mu \mathrm{L}$ of the slurry was drop-cast onto a glassy carbon (GC) electrode with a diameter of $5 \mathrm{~mm}$. The HER and OER tests were carried out by electrochemical workstation (CHI760E, Shanghai Chenhua) and Pine Modulated Speed Rotator with Pt silk as the counter electrode and $\mathrm{Ag} / \mathrm{AgCl}$ as reference electrode. The polarization curves for HER and OER were obtained at a scan rate of $5 \mathrm{mV} \mathrm{s}^{-1}$ under a rotation rate of $1,600 \mathrm{rpm}$ in $\mathrm{N}_{2}$-saturated $1 \mathrm{M} \mathrm{KOH}$ solution. Electrochemical impedance spectroscopy (EIS) test was performed from a frequency range of $10 \mathrm{kHz}$ to $0.01 \mathrm{~Hz}$ at a voltage of $-0.4 \mathrm{~V}$ (vs. RHE) for HER.

\section{RESULTS AND DISCUSSION}

The crystal structure of the as-prepared $\mathrm{Ni}_{2} \mathrm{P}$ was examined by XRD (Figure 1). The diffraction peaks are observed at 30.5, 31.8, $35.3,40.7,44.6,47.4,54.2,55.0,66.4,72.7$, and $74.8^{\circ}$, corresponding to planes (110), (101), (200), (111), (201), (210), (300), (211), (310), (311), and (400). The sample collected at $30 \mathrm{~h}$ can be indexed to the hexagonal phase of $\mathrm{Ni}_{2} \mathrm{P}$ (JCPDS 74-1,385) with $\mathrm{P}-62 \mathrm{~m}$ space group (the inset in Figure 1 in the atomic structure). There is no superfluous peak, indicating the successful synthesis of pure $\mathrm{Ni}_{2} \mathrm{P}$.

The nanostructures of obtained $\mathrm{Ni}_{2} \mathrm{P}$ nanowires were characterized by SEM and TEM. Figures $2 A, \mathbf{B}$ reveal that the $\mathrm{Ni}_{2} \mathrm{P}$ sample is composed of uniform nanowire clusters with lengths of about $10 \mu \mathrm{m}$ and diameters of about $100 \mathrm{~nm}$. Meanwhile, the orientation of most nanowires is in the same direction as in Figure 2A, and there are numerous hump-like particles on the surface of the nanowires in Figure 2B, exposing a large number of active sites during the electrocatalysis process. A 

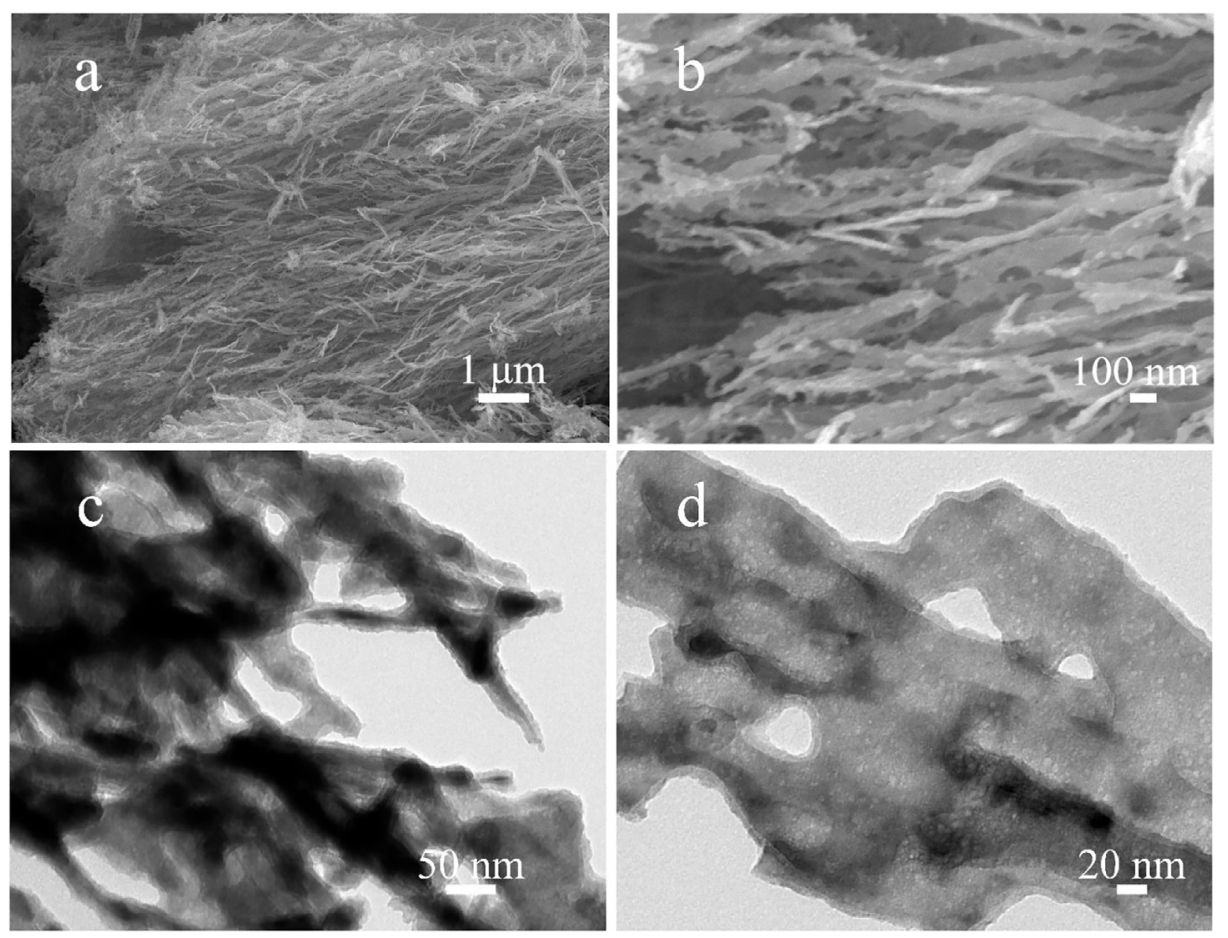

FIGURE 2 | (A, B) The SEM images of $\mathrm{Ni}_{2} \mathrm{P}$ nanowires; (C, D) The TEM images of $\mathrm{Ni}_{2} \mathrm{P}$ nanowires.
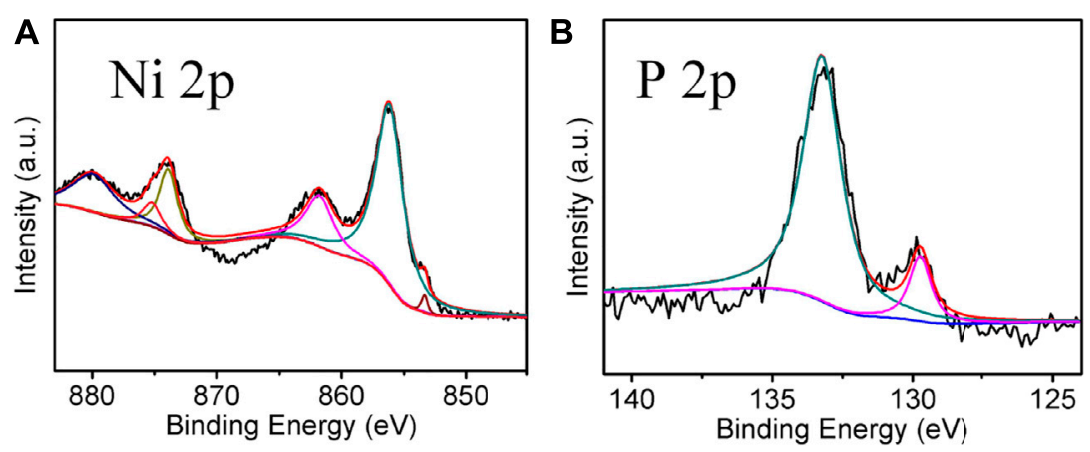

FIGURE 3 | XPS spectra (A) $\mathrm{Ni} 2 \mathrm{p}$, (B) $\mathrm{P} 2 \mathrm{p}$ regions for $\mathrm{Ni}_{2} \mathrm{P}$ nanowires.

TEM image in Figure 2C shows uniform nanowires of the $\mathrm{Ni}_{2} \mathrm{P}$ sample, and the inside of the nanowires reveals a large number of nanosized holes from the highly magnified TEM image in Figure 2D.

Figures 3A,B show the core-level XPS spectra of Ni and P elements of $\mathrm{Ni}_{2} \mathrm{P}$, respectively. As presented, the peaks located at $853.4,856.3$, and $861.9 \mathrm{eV}$ are associated with $\mathrm{Ni} 2 \mathrm{p}_{3 / 2}$. The peak at $853.6 \mathrm{eV}$ revealed that $\mathrm{Ni}$ species in $\mathrm{Ni}_{2} \mathrm{P}$ have a very small positive charge, while the peak at $129.7 \mathrm{eV}$ for $\mathrm{P} 2 \mathrm{p}$ indicates $\mathrm{Ni}_{2} \mathrm{P}$ has a very small negative charge (Wan et al., 2017). In addition, the peaks at 856.3 and $861.9 \mathrm{eV}$ in $\mathrm{Ni} 2 \mathrm{p}_{3 / 2}$ and the peak at $133.3 \mathrm{eV}$ in $\mathrm{P} 2 \mathrm{p}$ are likely to be ascribed to nickel phosphate formed on the surface of $\mathrm{Ni}_{2} \mathrm{P}$ due to the exposure of the sample to air (Xiao et al., 2016).
In order to explore the formation mechanism of $\mathrm{Ni}_{2} \mathrm{P}$ nanowires, a series of samples that underwent different reaction times were collected. The SEM images of the sample collected at $3 \mathrm{~h}$ in Figures 4A,D show the surface of a block has a uniform arrangement of projections with a length of about $200 \mathrm{~nm}$ and a diameter of about $40 \mathrm{~nm}$. The sample obtained at $7 \mathrm{~h}$ shows a larger cavity than that at $3 \mathrm{~h}$ as shown in Figures $4 \mathrm{~B}, \mathrm{E}$. Figures $4 \mathrm{C}, \mathrm{F}$ reveal that the sample obtained at $30 \mathrm{~h}$ is composed of nanowire clusters with the same orientation and length of about $10 \mu \mathrm{m}$ and a diameter of about $100 \mathrm{~nm}$. Taking red phosphorus as the phosphorus source and nickel acetate as the nickel source during hydrothermal reaction, the $\mathrm{Ni}_{2} \mathrm{P}$ nanowires were successfully synthesized. At first, red phosphorus is difficult to dissolve in deionized water. With the 

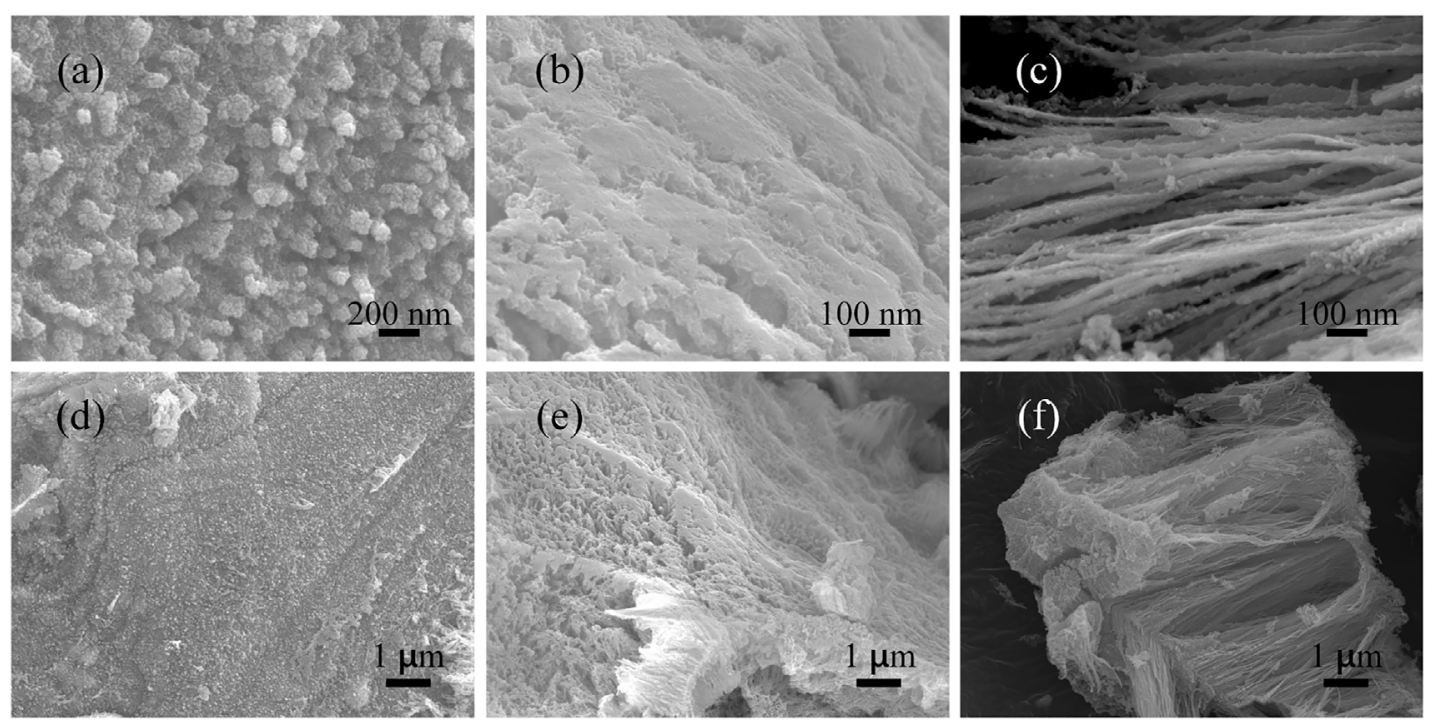

FIGURE 4 | SEM images of obtained samples from different reaction times: (A, D) 3 h; (B, D) 7 h; (C, F) 30 h.
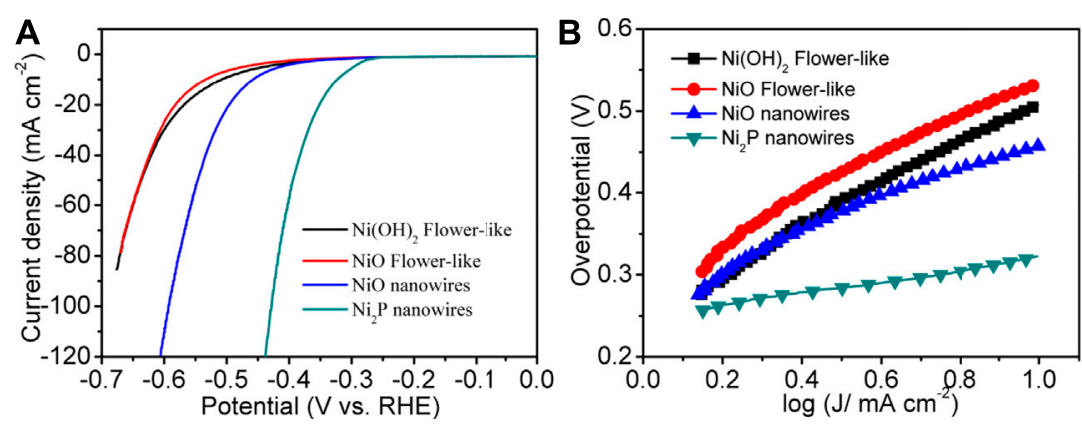

FIGURE 5 | (A) LSV curves of $\mathrm{Ni}_{2} \mathrm{P}$ nanowires, NiO nanowires, $\mathrm{Ni}(\mathrm{OH})_{2}$ flower-like at $5 \mathrm{mV} \mathrm{s}^{-1}$ in $1 \mathrm{M} \mathrm{KOH}$ from $-0.7-0 \mathrm{~V}$ vs. RHE. (B) Tafel plots of the HER activity.

hydrothermal process (process 1), red phosphorus was gradually decomposed to generate phosphine, and then the phosphine reacted with nickel ions in solution and nucleation occurs at the surface of the block. Following this (process 2), the block of red phosphorus was gradually consumed, and the nanowires gradually increase. Finally (process 3 ), the $\mathrm{Ni}_{2} \mathrm{P}$ nanowires were formed, accompanied with red phosphorus and nickel ions depleting.

Figure 5A shows the linear sweep voltammogram (LSV) curve of $\mathrm{Ni}_{2} \mathrm{P}$ nanowire catalysts at $5 \mathrm{mV} \mathrm{s}^{-1}$ after 20 cycles of cyclic voltammogram $\left(50 \mathrm{mV} \mathrm{s}^{-1}\right)$ activation. For comparative analysis, the LSV curves of the samples, i.e., $\mathrm{Ni}_{2} \mathrm{P}$ nanowires, $\mathrm{Ni}(\mathrm{OH})_{2}$ flower-like nanostructures, and $\mathrm{NiO}$ flower-like nanostructures (SEM images as shown in Supplementary Figure S1), were also measured at $5 \mathrm{mV} \mathrm{s}^{-1}$ with the same mass loadings of $0.175 \mathrm{mg} \mathrm{cm}^{-2}$. The polarization curves of $\mathrm{Ni}_{2} \mathrm{P}$ nanowires exhibit a remarkable electrocatalytic activity for HER with a small onset potential and overpotential $(\eta)$ to reach a current density of $10 \mathrm{~mA} \mathrm{~cm}^{-2}$. The ranking of the overpotentials for those catalysts is: $\mathrm{Ni}_{2} \mathrm{P}$ nanowires $(320 \mathrm{mV})<\mathrm{Ni}_{2} \mathrm{P}$ nanowires $(458 \mathrm{mV})<\mathrm{Ni}(\mathrm{OH})_{2}$ nanoflowers $(512 \mathrm{mV})<\mathrm{NiO}$ nanoflowers $(535 \mathrm{mV})$. It is clear that $\mathrm{Ni}_{2} \mathrm{P}$ nanowires exhibit the highest electrocatalytic activity toward HER. The Tafel slope for the $\mathrm{Ni}_{2} \mathrm{P}$ nanowires catalyst was about $73 \mathrm{mV} \mathrm{dec}{ }^{-1}$ (Figure 5B), much smaller than those of the $\mathrm{NiO}$ nanowires $\left(157 \mathrm{mV} \mathrm{dec}^{-1}\right)$, flowerlike $\mathrm{Ni}(\mathrm{OH})_{2}\left(234 \mathrm{mV} \mathrm{dec}{ }^{-1}\right)$, and flower-like $\mathrm{NiO}(213 \mathrm{mV}$ $\operatorname{dec}^{-1}$ ), which further confirmed the superior electrocatalytic HER kinetics of $\mathrm{Ni}_{2} \mathrm{P}$ nanowires.

To further understand the reason for the excellent electrocatalytic HER activity of $\mathrm{Ni}_{2} \mathrm{P}$ nanowires, EIS analysis was carried out (Figure 6). The charge transfer resistance under high frequency of $\mathrm{Ni}_{2} \mathrm{P}$ nanowire is low, which further implies its higher conductivity. The lower charge transfer resistance and higher diffusion of electrolyte ions indicate good electronic conductivity and high $\mathrm{OH}^{-}$ion transfer speed in the interface of active materials/electrolyte. The aforesaid electrochemical performances reveal that $\mathrm{Ni}_{2} \mathrm{P}$ nanowire clusters are an efficient and sturdy electrocatalyst for HER in strongly basic media. 


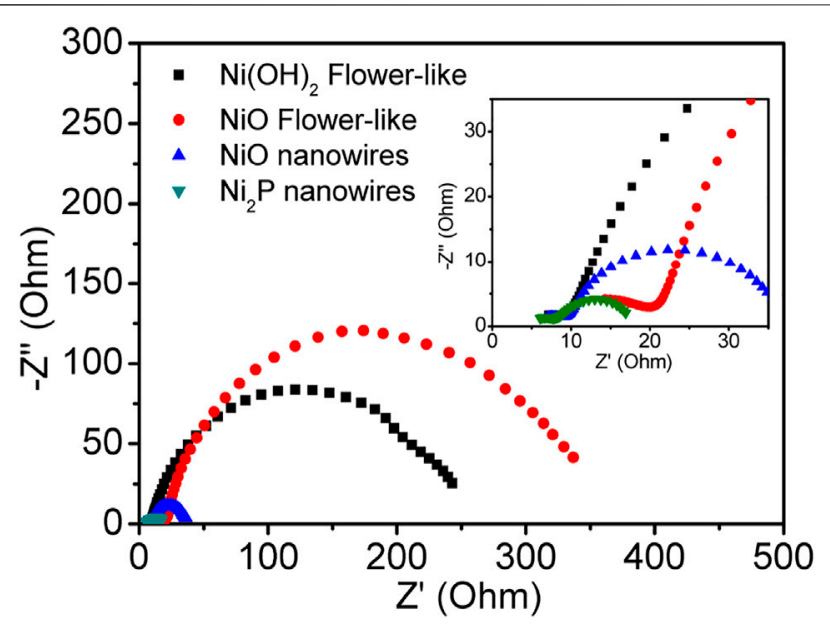

FIGURE 6 | Electrochemical impedance spectrum of $\mathrm{Ni}_{2} \mathrm{P}$ nanowires.

Figure 7A shows the linear sweep voltammograms (LSV) curve of $\mathrm{Ni}_{2} \mathrm{P}$ nanowire catalyst at $5 \mathrm{mV} \mathrm{s}^{-1}$ after 20 cycles of cyclic voltammogram (at the scan rate of $50 \mathrm{mV} \mathrm{s}^{-1}$ ) activation. For comparative analysis, the LSV curves of $\mathrm{NiO}$ nanowires, $\mathrm{Ni}(\mathrm{OH})_{2}$ flower-like, and $\mathrm{NiO}$ flower-like catalysts were also measured at $5 \mathrm{mV} \mathrm{s}^{-1}$ with the same mass loadings of $0.175 \mathrm{mg} \mathrm{cm}^{-2}$. The polarization curves of $\mathrm{Ni}_{2} \mathrm{P}$ nanowires exhibit a higher current density and more negative OER overpotential of $280 \mathrm{mV}$ than those of $\mathrm{NiO}$ nanowires $(310 \mathrm{mV}), \mathrm{Ni}(\mathrm{OH})_{2}$ flower-like $(370 \mathrm{mV})$, and $\mathrm{NiO}$ flower-like $(390 \mathrm{mV})$. In order to further study the polarization property, the
LSV curves of $\mathrm{Ni}_{2} \mathrm{P}$ nanowires at different scan rates were displayed in Figure 7B. It indicates that the polarization curves have no difference in addition to the intensity of the oxidation peaks. This oxidation peak is also reversible for $\mathrm{Ni}_{2} \mathrm{P}$ nanowires as observed from the cyclic voltammogram (Supplementary Figure S2). The Tafel slope for the $\mathrm{Ni}_{2} \mathrm{P}$ nanowires catalyst was about $46 \mathrm{mV} \mathrm{dec}^{-1}$ (Figure 7C), much smaller than those of the $\mathrm{NiO}$ nanowires $\left(52.6 \mathrm{mV} \mathrm{dec}{ }^{-1}\right)$, flower-like $\mathrm{Ni}(\mathrm{OH})_{2} \quad\left(145 \mathrm{mV} \mathrm{dec}^{-1}\right)$, and

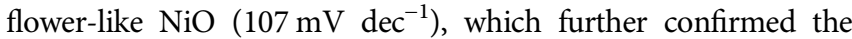
superior electrocatalytic OER kinetics of $\mathrm{Ni}_{2} \mathrm{P}$ nanowires. The stability of the $\mathrm{Ni}_{2} \mathrm{P}$ nanowires for OER was tested in amperometric i-t curve at $1.7 \mathrm{~V}$ (vs. RHE) for $12 \mathrm{~h}$ (Figure 7D), indicating its good durability.

\section{CONCLUSION}

In summary, we firstly synthesized $\mathrm{Ni}_{2} \mathrm{P}$ nanowires using a facile one-step hydrothermal approach. The as-synthesized $\mathrm{Ni}_{2} \mathrm{P}$ is composed of nanowire clusters with a uniform length of about $10 \mu \mathrm{m}$ and a diameter of about $40 \mathrm{~nm}$. There are a large number of nanoparticles on the surface of the nanowires, providing a large number of active sites during the electrocatalysis process. The overpotential of $\mathrm{Ni}_{2} \mathrm{P}$ nanowires is $320 \mathrm{mV}$ and clearly

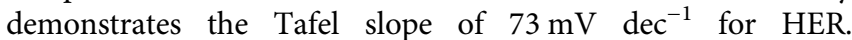
Meanwhile, the $\mathrm{Ni}_{2} \mathrm{P}$ nanowires show excellent electrocatalytic OER activity with overpotential of $1.51 \mathrm{~V}$ (vs. RHE) and Tafel slope of $46 \mathrm{mV} \mathrm{dec}^{-1}$. This work provides good guidance for the rational design of nickel phosphides with unique nanostructures for highly efficient overall water splitting.
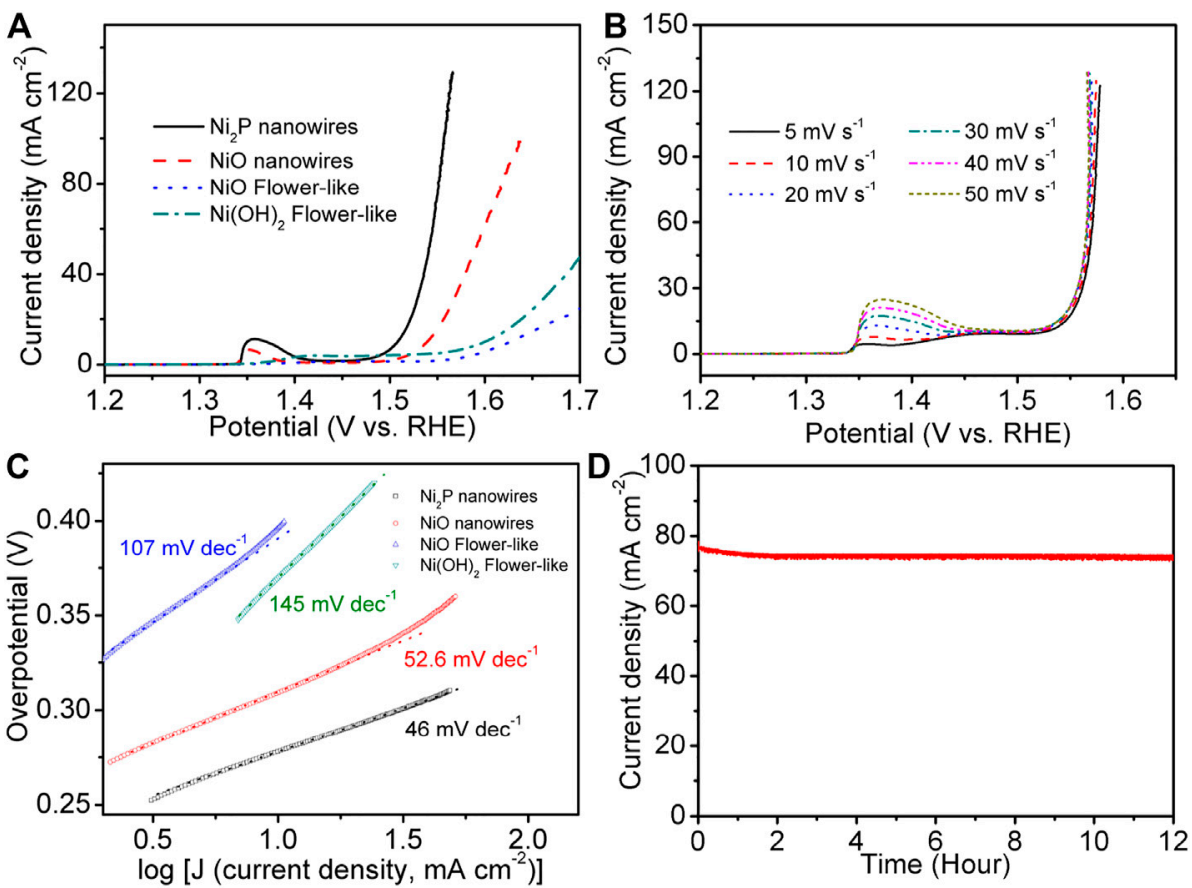

FIGURE 7 | (A) LSV curves of $\mathrm{Ni}_{2} \mathrm{P}$ nanowires, NiO nanowires, $\mathrm{Ni}(\mathrm{OH})_{2}$ flower-like at $5 \mathrm{mV} \mathrm{s}^{-1}$ in $1 \mathrm{M} \mathrm{KOH}$. (B) LSV curves of Ni $\mathrm{L}_{2} \mathrm{P}$ nanowires at different scan rates. (C) Tafel plots of the OER activity. (D) The stability of the $\mathrm{Ni}_{2} \mathrm{P}$ nanowires tested in amperometric i-t curve at $1.7 \mathrm{~V}$ vs. RHE. 


\section{DATA AVAILABILITY STATEMENT}

The raw data supporting the conclusion of this article will be made available by the authors, without undue reservation.

\section{AUTHOR CONTRIBUTIONS}

All authors listed have made a substantial, direct, and intellectual contribution to the work and approved it for publication.

\section{REFERENCES}

Chen, Y., Fu, K., Zhu, S., Luo, W., Wang, Y., Li, Y., et al. (2016). Reduced Graphene Oxide Films with Ultrahigh Conductivity as Li-Ion Battery Current Collectors. Nano Lett. 16, 3616-3623. doi:10.1021/acs.nanolett.6b00743

Danilovic, N., Subbaraman, R., Strmcnik, D., Chang, K.-C., Paulikas, A. P., Stamenkovic, V. R., et al. (2012). Enhancing the Alkaline Hydrogen Evolution Reaction Activity through the Bifunctionality of $\mathrm{Ni}(\mathrm{OH}) 2 /$ Metal Catalysts. Angew. Chem. Int. Ed. 51, 12495-12498. doi:10.1002/anie.201204842

Debe, M. K. (2012). Electrocatalyst Approaches and Challenges for Automotive Fuel Cells. Nature 486, 43-51. doi:10.1038/nature11115

Feng, L.-L., Yu, G., Wu, Y., Li, G.-D., Li, H., Sun, Y., et al. (2015). High-Index Faceted Ni3S2 Nanosheet Arrays as Highly Active and Ultrastable Electrocatalysts for Water Splitting. J. Am. Chem. Soc. 137, 14023-14026. doi:10.1021/jacs.5b08186

Feng, L., Vrubel, H., Bensimon, M., and Hu, X. (2014). Easily-prepared dinickel phosphide (Ni2P) nanoparticles as an efficient and robust electrocatalyst for hydrogen evolution. Phys. Chem. Chem. Phys. 16, 5917-5921. doi:10.1039/ c4cp00482e

Gan, Y., Wang, C., Chen, X., Liang, P., Wan, H., Liu, X., et al. (2020). High conductivity Ni12P5 nanowires as high-rate electrode material for batterysupercapacitor hybrid devices. Chem. Eng. J. 392, 123661. doi:10.1016/ j.cej.2019.123661

Gong, M., Zhou, W., Tsai, M.-C., Zhou, J., Guan, M., Lin, M.-C., et al. (2014). Nanoscale Nickel Oxide/Nickel Heterostructures for Active Hydrogen Evolution Electrocatalysis. Nat. Commun. 5, 4695. doi:10.1038/ncomms5695

Hellstern, T. R., Benck, J. D., Kibsgaard, J., Hahn, C., and Jaramillo, T. F. (2016). Engineering Cobalt Phosphide (CoP) Thin Film Catalysts for Enhanced Hydrogen Evolution Activity on Silicon Photocathodes. Adv. Energ. Mater. 6, 1501758. doi:10.1002/aenm.201501758

Huang, H., Yu, C., Zhao, C., Han, X., Yang, J., Liu, Z., et al. (2017). Iron-tuned Super Nickel Phosphide Microstructures with High Activity for Electrochemical Overall Water Splitting. Nano Energy 34, 472-480. doi:10.1016/j.nanoen.2017.03.016

Ji, J., Wan, H., Zhang, B., Wang, C., Gan, Y., Tan, Q., et al. (2021). Co 2+/3+/4+ -Regulated Electron State of Mn-O for Superb Aqueous Zinc-Manganese Oxide Batteries. Adv. Energ. Mater. 11 (6), 2003203. doi:10.1002/ aenm.202003203

Kuang, P., Tong, T., Fan, K., and Yu, J. (2017). In Situ Fabrication of Ni-Mo Bimetal Sulfide Hybrid as an Efficient Electrocatalyst for Hydrogen Evolution over a Wide pH Range. ACS Catal. 7, 6179-6187. doi:10.1021/ acscatal.7b02225

Li, H., Wang, W., Gong, Z., Yu, Y., Piao, l., Chen, H., et al. (2015). Shape-controlled Synthesis of Nickel Phosphide Nanocrystals and Their Application as Hydrogen Evolution Reaction Catalyst. J. Phys. Chem. Sol. 80, 22-25. doi:10.1016/j.jpcs.2014.12.013

Li, J., Li, J., Zhou, X., Xia, Z., Gao, W., Ma, Y., et al. (2016). Highly Efficient and Robust Nickel Phosphides as Bifunctional Electrocatalysts for Overall WaterSplitting. ACS Appl. Mater. Inter. 8, 10826-10834. doi:10.1021/acsami.6b00731

Li, Q., Ma, J., Wang, H., Yang, X., Yuan, R., and Chai, Y. (2016). Interconnected Ni $2 \mathrm{P}$ nanorods grown on nickel foam for binder free lithium ion batteries. Electrochimica Acta 213, 201-206. doi:10.1016/j.electacta.2016.07.105

\section{FUNDING}

This work was financially supported by the National Natural Science Foundation of China (No. 51305094).

\section{SUPPLEMENTARY MATERIAL}

The Supplementary Material for this article can be found online at: https://www.frontiersin.org/articles/10.3389/fchem.2021.773018/ full\#supplementary-material

Li, T., Xu, Y., Xing, F., Cao, X., Bian, J., Wang, N., et al. (2017). Boosting Photoelectrochemical Water Splitting by TENG-Charged Li-Ion Battery. Adv. Energ. Mater. 7, 1700124. doi:10.1002/aenm.201700124

Liao, W., and Huang, L. (2017). Improving the Oxygen Evolution Performance of Nickel Phosphide Nanoparticles with Satellite Nitrogen-doped Carbon Quantum Dots. Mater. Lett. 209, 106-110. doi:10.1016/ j.matlet.2017.07.127

Menezes, P. W., Indra, A., Das, C., Walter, C., Göbel, C., Gutkin, V., et al. (2016). Uncovering the Nature of Active Species of Nickel Phosphide Catalysts in Highperformance Electrochemical Overall Water Splitting. ACS Catal. 7, 103-109. doi:10.1021/acscatal.6b02666

Pan, Y., Liu, Y., Zhao, J., Yang, K., Liang, J., Liu, D., et al. (2015). Monodispersed Nickel Phosphide Nanocrystals with Different Phases: Synthesis, Characterization and Electrocatalytic Properties for Hydrogen Evolution. J. Mater. Chem. A. 3, 1656-1665. doi:10.1039/c4ta04867a

Qiu, Z., Ma, Y., Edström, K., Niklasson, G. A., and Edvinsson, T. (2017). Controlled Crystal Growth Orientation and Surface Charge Effects in SelfAssembled Nickel Oxide Nanoflakes and Their Activity for the Oxygen Evolution Reaction. Int. J. Hydrogen Energ. 42, 28397-28407. doi:10.1016/ j.ijhydene.2017.09.117

Rao, Y., Wang, Y., Ning, H., Li, P., and Wu, M. (2016). Hydrotalcite-like Ni(OH)2 Nanosheets In Situ Grown on Nickel Foam for Overall Water Splitting. ACS Appl. Mater. Inter. 8, 33601-33607. doi:10.1021/acsami.6b11023

Sivanantham, A., Ganesan, P., and Shanmugam, S. (2016). Hierarchical NiCo2S4Nanowire Arrays Supported on Ni Foam: An Efficient and Durable Bifunctional Electrocatalyst for Oxygen and Hydrogen Evolution Reactions. Adv. Funct. Mater. 26, 4661-4672. doi:10.1002/adfm.201600566

Stern, L.-A., Feng, L., Song, F., and Hu, X. (2015). Ni2P as a Janus catalyst for water splitting: the oxygen evolution activity of Ni2P nanoparticles. Energy Environ. Sci. 8, 2347-2351. doi:10.1039/c5ee01155h

Swierk, J. R., and Mallouk, T. E. (2017). Correction: Design and Development of Photoanodes for Water-Splitting Dye-Sensitized Photoelectrochemical Cells. Chem. Soc. Rev. 46, 559. doi:10.1039/c6cs90124g

Tan, Q., Li, X., Zhang, B., Chen, X., Tian, Y., Wan, H., et al. (2020). Valence Engineering via In Situ Carbon Reduction on Octahedron Sites Mn 3 O 4 for Ultra-Long Cycle Life Aqueous Zn-Ion Battery. Adv. Energ. Mater. 10 (38), 2001050. doi:10.1002/aenm.202001050

Tang, C., Gan, L., Zhang, R., Lu, W., Jiang, X., Asiri, A. M., et al. (2016). Ternary FexCo1-xP Nanowire Array as a Robust Hydrogen Evolution Reaction Electrocatalyst with Pt-like Activity: Experimental and Theoretical Insight. Nano Lett. 16, 6617-6621. doi:10.1021/acs.nanolett.6b03332

Vij, V., Sultan, S., Harzandi, A. M., Meena, A., Tiwari, J. N., Lee, W.-G., et al. (2017). Nickel-Based Electrocatalysts for Energy-Related Applications: Oxygen Reduction, Oxygen Evolution, and Hydrogen Evolution Reactions. ACS Catal. 7, 7196-7225. doi:10.1021/acscatal.7b01800

Wan, H., Li, L., Chen, Y., Gong, J., Duan, M., Liu, C., et al. (2017). One pot synthesis of Ni 12 P 5 hollow nanocapsules as efficient electrode materials for oxygen evolution reactions and supercapacitor applications. Electrochimica Acta 229, 380-386. doi:10.1016/j.electacta.2017.01.169

Wang, C., Song, Z., Wan, H., Chen, X., Tan, Q., Gan, Y., et al. (2020). Ni-Co Selenide Nanowires Supported on Conductive Wearable Textile as Cathode for Flexible Battery-Supercapacitor Hybrid Devices. Chem. Eng. J. 400, 125955. doi:10.1016/j.cej.2020.125955 
Wang, J., Cui, W., Liu, Q., Xing, Z., Asiri, A. M., and Sun, X. (2016). Recent Progress in Cobalt-Based Heterogeneous Catalysts for Electrochemical Water Splitting. Adv. Mater. 28, 215-230. doi:10.1002/adma.201502696

Wang, P., Song, F., Amal, R., Ng, Y. H., and Hu, X. (2016). Efficient Water Splitting Catalyzed by Cobalt Phosphide-based Nanoneedle Arrays Supported on Carbon Cloth. ChemSusChem 9, 472-477. doi:10.1002/ cssc.201501599

Wang, Q., Hisatomi, T., Jia, Q., Tokudome, H., Zhong, M., Wang, C., et al. (2016). Scalable water splitting on particulate photocatalyst sheets with a solar-tohydrogen energy conversion efficiency exceeding 1\%. Nat. Mater 15, 611-615. doi: $10.1038 / \mathrm{nmat} 4589$

Wang, X., Li, W., Xiong, D., and Liu, L. (2016). Fast Fabrication of Self-supported Porous Nickel Phosphide Foam for Efficient, Durable Oxygen Evolution and Overall Water Splitting. J. Mater. Chem. A. 4, 5639-5646. doi:10.1039/c5ta10317g

Xiao, J., Lv, Q., Zhang, Y., Zhang, Z., and Wang, S. (2016). One-step Synthesis of Nickel Phosphide Nanowire Array Supported on Nickel Foam with Enhanced Electrocatalytic Water Splitting Performance. RSC Adv. 6, 107859-107864. doi:10.1039/c6ra20737e

Xiong, D., Wang, X., Li, W., and Liu, L. (2016). Facile Synthesis of Iron Phosphide Nanorods for Efficient and Durable Electrochemical Oxygen Evolution. Chem. Commun. 52, 8711-8714. doi:10.1039/c6cc04151e

Yu, X.-Y., Feng, Y., Guan, B., Lou, X. W., and Paik, U. (2016). Carbon Coated Porous Nickel Phosphides Nanoplates for Highly Efficient Oxygen Evolution Reaction. Energ. Environ. Sci. 9, 1246-1250. doi:10.1039/c6ee00100a

Zhang, C., Park, S.-H., O’Brien, S. E., Seral-Ascaso, A., Liang, M., Hanlon, D., et al. (2017). Liquid Exfoliation of Interlayer Spacing-Tunable 2D Vanadium Oxide Nanosheets: High Capacity and Rate Handling Li-ion Battery Cathodes. Nano Energy 39, 151-161. doi:10.1016/j.nanoen.2017.06.044

Zhang, L., Xiao, J., Wang, H., and Shao, M. (2017). Carbon-Based Electrocatalysts for Hydrogen and Oxygen Evolution Reactions. ACS Catal. 7, 7855-7865. doi:10.1021/acscatal.7b02718
Zhang, T., Wu, M.-Y., Yan, D.-Y., Mao, J., Liu, H., Hu, W.-B., et al. (2018). Engineering Oxygen Vacancy on $\mathrm{NiO}$ Nanorod Arrays for Alkaline Hydrogen Evolution. Nano Energy 43, 103-109. doi:10.1016/j.nanoen.2017.11.015

Zhao, X., Wan, H., Liang, P., Wang, N., Wang, C., Gan, Y., et al. (2021). Favorable anion adsorption/desorption of high rate NiSe2 nanosheets/hollow mesoporous carbon for battery-supercapacitor hybrid devices. Nano Res. 14, 2574-2583. doi:10.1007/s12274-020-3257-z

Zhou, X., Jin, J., Zhu, X., Huang, J., Yu, J., Wong, W.-Y., et al. (2016). New Co(OH) $2 / \mathrm{CdS}$ nanowires for efficient visible light photocatalytic hydrogen production. J. Mater. Chem. A. 4, 5282-5287. doi:10.1039/c6ta00325g

Zhu, T., Zhu, L., Wang, J., and Ho, G. W. (2016). In Situ chemical etching of tunable 3D Ni3S2 superstructures for bifunctional electrocatalysts for overall water splitting. J. Mater. Chem. A. 4, 13916-13922. doi:10.1039/c6ta05618k

Conflict of Interest: The authors declare that the research was conducted in the absence of any commercial or financial relationships that could be construed as a potential conflict of interest.

Publisher's Note: All claims expressed in this article are solely those of the authors and do not necessarily represent those of their affiliated organizations, or those of the publisher, the editors and the reviewers. Any product that may be evaluated in this article, or claim that may be made by its manufacturer, is not guaranteed or endorsed by the publisher.

Copyright (c) 2021 Xiang, Zhang, Zhang and Shen. This is an open-access article distributed under the terms of the Creative Commons Attribution License (CC BY). The use, distribution or reproduction in other forums is permitted, provided the original author(s) and the copyright owner(s) are credited and that the original publication in this journal is cited, in accordance with accepted academic practice. No use, distribution or reproduction is permitted which does not comply with these terms. 